\title{
A Farmacovigilância
}

Suely Rozenfeld *

Iracema T. M. Rangel ${ }^{* *}$

\section{O PANORAMA INTERNACIONAL}

A terapêutica farmacológica atual é uma prática relativamente recente. Até o século XIX a maioria dos medicamentos eram remédios naturais de estrutura química e natureza desconhecidas. No início do século XX foram introduzidos na terapêtica os primeiros barbitúricos, os derivados arsenicais e a insulina, porém somente nos anos 40 houve a introdução maciça de novos farmacos que abririam possibilidades de cura até então inalcançáveis, sobretudo no campo das enfermidades infecciosas. Nos anos 30 surgiram as sulfamida, a fenitoína e a peditina. Nos anos 40 são descobertos a penicilina, a estreptomicina, a clortetraciclina e o clorafenicol. Nos anos 50 surgiram entre outros a isotiazida e a procainamida. $\mathrm{Na}$ atualidade, as especialidades farmacêuticas ocupam a maior parte das vendas no comércio farmacêutico, embora há 40 anos não representassem nem $25 \%$ das vendas neste setor. Os determinantes de consumo se alteraram enormemente após a Segunda Guerra Mundial gerando o fenômeno da "explosão farmacológica".

Os efeitos benéficos potenciais dos farmacos foram percebidos após a introdução dos primeiros antibióticos. Naquela época porém, já se conhecia a possibilidade dos medicamentos produzirem reações adversas; por exemplo: já haviam sido descritos casos de anemia aplástica e de agranulocitose atribuídos a medicamentos. Entretanto, foi nos anos 30 após uma epidemia que produziu mais de 100 mortes devido ao uso de dietilenoglicol como excipiente de um xarope, nos Estados Unidos, que o problema das reaçōes adversas passou a ter repercussões sanitárias, a ponto de produzir modificaçōes na legislação farmacêutica norte-americana.

Em 1961 a tragédia da talidomida, que originou o nascimento de aproximadamente 4000 crianças com

- Médica sanitarista. Coordenadora do NEME/ENSPI

FIOCRUZ

** Médica cardiologista. Membro do NEME/ENSP/FIOCRUZ focomelia em todo o mundo, foi um verdadeiro ponto de partida; a percepção do dano causado por este medicamento e o forte impacto do episódio sobre a opinião pública constituíram o mais firme impulso para o de-

Cademos de Saúde Pública, RJ, 4 (3): 336-341, jul/set, 1988 
senvolvimento de uma nova legislação sobre medicamentos na maioria dos países europeus. Esta legislação dirigiu-se sobretudo para a garantia de segurança dos medicamentos, baseada nos estudos em animais, com resultados raramente extrapolados para a espécie humana. Lamentavelmente em poucos paises se desenvolve o exame da suposta eficácia clínica dos medicamentos.

Os elementos de análise apresentados até agora, foram considerados numa definição dada pela Organização Mundial da Saúde (OMS) sobre a relação beneficio/risco de um farmaco: "é um meio para expressar um juigamento referente ao papel de um farmaco na prática médica, baseado em dados sobre eficácia e segurança, junto a considerações sobre a enfermidade na qual se emprega, etc." Este conceito pode ser aplicaito a um só farmaco ou na comparaçăo entre dois ou his farmacos utilizados para uma mesma indicação. Essta definição indica que é necessário considerar diversos critérios com o objetivo de definir o papel dos medicamentos na prática médica: prioridades sanitórias e necessidades de uma população, sua situação epiderilológica, a disponibilidade de recursos, a necessidade de desenvolver programas de vigilância de medicamentos, a educaçäo dos médicos que prescrevem e dos consumidores e finalmente o uso adequado dos recursos financeiros.

A Organizaçäo Mundial da Saúde assumiu um papel ativo nestas discussóes, particularmente na organização dos sistemas de monitorização de notificaçốes espontâneas adversas na Austrália, Canadá, Tchecoslováquia, Estados Unidos, Irlanda, Japão, Nova Zelândia, Países Baixos, Países Escandinavos, Reino Unido e República Federal da Alemanha. Atualmente existem centros deste tipo em 25 países.

Em geral os sistemas de monitorização desenvolvidos am cada pais seguem o mesmo esquema. Organiza-se um Centro nacional para estimular as notificações espontâneas de reaçöes adversas, recolher e processar as notificaçōes e finalmente elaborar e distribuir os resultados mair significativos.

Em 1968 iniciou-se um programa piloto de investigaçăo da OMS. Dez países membros concordaram em enviar notificaçôes sobre reaçōes adversas recebidas por seus resfectivos centros nacionais de monitorizaçăo. Quando o programa foi avaliado em 1970, a Assemblểa Múndial de Saúde chegon à conclusão de qus. o programa deveria ser perman ente. Desde então, un nimero cada ver, maior de países se associou ao 
programa da OMS. Desde 1978 funciona em Uppsala (Suécia) o Centro Colaborativo da OMS para o Programa Internacional de Farmacovigilância cujas funçōes são:

- recolher, analisar, armazenar e tabular informaçōes dos centros nacionais que participam do programa;

- fazer seguimento da literatura científica no campo das reaçōes adversas a medicamentos;

- desenvolver métodos para analisar a incidência e significado das reaçōes adversas e para obter sinais de aviso precoce sobre reaçöes adversas a medicamentos;

- iniciar e realizar estudos científicos sobre o aparecimento de reaçōes adversas a medicamentos;

- repassar à OMS os resultados obtidos através das atividades citadas nos pontos anteriores e auxiliá-la na preparação de informações relevantes para sua distribuição aos centros nacionais ou a outros centros;

- auxiliar o estabelecimento e desenvolvimento de centros nacionais de farmacovigilância em países em vias de desenvolvimento e colaborar para a melhoria de seus programas de farmacovigilância;

- em colaboração com a OMS, organizar reuniỏes científicas para revisar e avaliar as informaçōes recolhidas pelo centro.

\section{A SITUAÇÃO DO BRASIL}

O Brasil é um país no qual a questão dos medicamentos já tem alguma tradição. A produção de remédios surge paralela à medicina popular exercida desde o período colonial, através de dezenas de pequenos empreendimentos, freqüentemente familiares que dedicavam-se à produção de medicamentos a partir de extratos vegetais. Após a Segunda Guerra Mundial estruturaram-se pequenas e inúmeras indústrias, que por um lado mantêm a tradição na fabricação de produtos à base de plantas, e por outro lado, iniciam o fabrico em larga escala de antibióticos, agentes cardiovasculares, psicotrópicos e outros, aproveitando a expansão da indústria e a descoberta de novos farmacos a nível internacional. $\mathrm{Na}$ atualidade, o Brasil produz internamente parte (entre 15 e $20 \%$ ) da matéria-prima utilizada na produção de medicamentos, sendo duas ou três dezenas de farmacos da responsabilidade de laboratórios nacionais.

Contrapondo-se ao desenvolvimento na área da fabricaçāo, observa-se certa estagnação nas demais áreas, particularmente no que tange ao ensino e à

Cadernos de Saúde Pública, RJ, 4 (3): 336-341, jul/set, 1988 
pesquisa em farmacologia e epidemiologia do medicamento. Sabe-se que inúmeras escolas médicas ofereciam décadas atrás a disciplina de Terapêutica. Com o passar dos tempos abandonaram-na sem substituí-la pelos conhecimentos da farmacologia clínica. Quanto aos estudos epidemiológicos, que visam avaliar o impacto do uso dos produtos farmacêuticos na comunidade, por constituírem um campo de estudos relativamente recente, praticamente inexistem em nosso País, e os poucos grupos dedicados a este tema, em geral, especializaram-se no estudo de classes terapêuticas específicas (fitoterápicos, psicotrópicos etc.) ou na caracterização da oferta e do consumo de produtos.

Raramente são encontradas investigaçōes que utilizam os modemos instrumentos empregados nos países europeus e nos Estados Unidos nos estudos: das reaçōes inesperadas, sejam elas graves ou não; das particularidades de ordem geográfica, étnica ou nutricional que afetam o resultado da farmacoterapia; do impacto econômico dos diversos esquemas terapêuticos empregados na prática médica corrente, e assim por diante. Inexistem centros de desenvolvimento de programas amplos, diversificados e abrangendo todo o espectro de possibilidades metodológicas e temáticas da moderna farmacovigilância.

Conseqüentemente nāo tem sido produzida literatura suficiente sob a forma de livros-texto, artigos em revistas, boletins informativos e outros em quantidade compativel com as necessidades de um país que é o sétimo em vendas no "ranking" mundial. Tampouco têm sido produzidas informaçōes para fazer frente ao imenso arsenal publicitário que a indústria farmacêutica impõe ao médico que prescreve. Com isso, há carência absoluta e relativa de conhecimentos originais formulados por grupos locais independentes dos interesses comerciais, que dêem conta de avaliar os efeitos dos farmacos no organismo humano (farmacologia clínica) e na comunidade (epidemiologia e farmacovigilância).

Como era de se esperar, as conseqüências deste fato sobre a qualidade da assistência médica são profundas e graves. Às distorçöes sobejamente conhecidas da oferta de farmacos em nosso meio (excesso de produtos similares com nomes distintos e fórmulas levemente modificadas; altos percentuais de especialidades farmacêuticas contendo associaçōes em doses fixas; bulas e propagandas alegando propriedades miraculosas e omitindo efeitos colaterais) agregaram-se aquelas 
geradas no próprio sistema prestador de serviços médico-assistenciais.

Claro está que na vigência do processo de Reforma Sanitária, no qual vão se sedimentando antigas propostas do movimento sanitário - tais como a unificação e descentralização do Sistema de Atenção ì Saúde e integração da assistência médica preventiva e curativa - impõe-se uma revisão do panorama da assistência farmacêutica, que deverá gerar desdobramentos não somente na reestruturação das instituiçōes responsáveis (quanto a atribuições, propósitos e recursos), como também mudanças comportamentais no que se refere às normas e padrōes de prescriçăo. $O$ próprio percentual de gastos na compra de medicamentos pela Previdência Social - cerca de 3\% dos gastos correntes - deverá ser progressivanente aumentado, na medida em que os altos custos unitários das especialidades farmacêuticas adquiridas ias farnácias, tornarão os meios terapêuticos inacessiveis para faixas de população cada vez maiores.

\section{PERSPECTIVAS ATUAIS}

Tais mudanças exigem grupos dedicados exclusivamente a investigação e produção de conhecimentos novos, confíaveis, independentes, crm base na realidade nacional e nos modemos parâmetros conceituais e metodológicos fornecidos pela epidemiologia dos medicamentos e farmacologia clínica.

Buscando atender a estes objetivos, a Escola $\mathrm{Na}$ cional de Saúde Pública criou, em 1987, o Núcleo de Estudos de Medicamentos (NEME), constituído por profissionais que no período de 85/87 estiveram envolvidos no esforço de reestruturação da Vigilância Sanitária (DIMED/SNVS/MS).

Durante o ano de 1987 o NEME desenvolveu atividades docentes, seminários e realizou durante 0 mês de outubro a Disciplina de Vigilância Sanitária no Módulo de Planejamento e Administraçāo do Curso Básico de Especializaçāo em Saúde Públíca.

Para o ano de 1988 pretende-se continuar este esforço, procurando aprofundar o trabalho de docência e investigaçāo na área de farmacos e contribuir para a criaçăo de programas de farmacovigilância em nosso meio.

\section{REFERENCIAS BIBLIOGRÁFICAS}

ALMEIDA, C. alii. Desinformaçio farmectuticarCi. e Cult., 39 (4): 367-70, 1987. 
PALDY, 3 . 5. et alii. Estudo crítico sobre os antimicrobianos corcere qlizade no Brasil. R. Assoc. Méd. Bras., 30 (11/12), 1934

CORDLRO, H. A insisiriria da saúde no Brasil. Rio de Janeiro, Cron, 3880.

FRENYEL, jo et alii. Tscnologia e competição na indístria farmacêutica. Is de Taneiro. FINEP/Centro de Estudos e Pesquisas, 1978. nimse.

GRIFIIN, J. P. y WEBER, J. C. P. Voluntary Systems of reaction reproring Adv Drug Reac Ac. Pois Rev. 1986, 1, 23-25.

GRT: IN, J. P. y WEBER, I. C. P. Voluniary Systems of adverse reaction reporting I. Adv Drug React Ac. Pois Rev. 1985, A. $213 / 2 \%$

FFORTE, I, R. \& TOGNONI, G. Estudios de utilización de es iscumentos y de farmucovigilancia. In: Principios de epidemio 'ogka sel medicamento. Miadrid, Salvat, 1983.

CRUANIZAÇÃO MUNDIAL DA SAÚDE. A seleçấo de medica. smontos essenciais. Genebra. 1977 (Série de informes téenicos, 615). 